ORIGINAL ARTICLE

\title{
Benzene and naphthalene in air and breath as indicators of exposure to jet fuel
}

\author{
P P Egeghy, L Hauf-Cabalo, R Gibson, S M Rappaport
}

Occup Environ Med 2003;60:969-976

See end of article for
authors' affiliations
$\ldots \ldots \ldots \ldots \ldots \ldots \ldots . . . .$.
Correspondence to:
Prof. S M Rappaport,
Department of
Environmental Sciences
and Engineering, School of
Public Health, University of
North Carolina at Chapel
Hill, Chapel Hill, North
Carolina 27599-7431,
USA; smr@unc.edu
Accepted
14 February 2003
........................
Aims: To estimate exposures to benzene and naphthalene among military personnel working with jet fuel (JP-8) and to determine whether naphthalene might serve as a surrogate for JP-8 in studies of health effects.

Methods: Benzene and naphthalene were measured in air and breath of 326 personnel in the US Air Force, who had been assigned a priori into low, moderate, and high exposure categories for JP-8.

Results: Median air concentrations for persons in the low, moderate, and high exposure categories were 3.1, 7.4, and $252 \mu \mathrm{g}$ benzene $/ \mathrm{m}^{3}$ air, $4.6,9.0$, and $11.4 \mu \mathrm{g}$ benzene $/ \mathrm{m}^{3}$ breath, $1.9,10.3$, and $485 \mu \mathrm{g}$ naphthalene $/ \mathrm{m}^{3}$ air, and $0.73,0.93$, and $1.83 \mu \mathrm{g}$ naphthalene $/ \mathrm{m}^{3}$ breath, respectively. In the moderate and high exposure categories, $5 \%$ and $15 \%$ of the benzene air concentrations, respectively, were above the 2002 threshold limit value (TLV) of $1.6 \mathrm{mg} / \mathrm{m}^{3}$. Multiple regression analyses of air and breath levels revealed prominent background sources of benzene exposure, including cigarette smoke. However, naphthalene exposure was not unduly influenced by sources other than JP-8. Among heavily exposed workers, dermal contact with JP-8 contributed to air and breath concentrations along with several physical and environmental factors.

Conclusions: Personnel having regular contact with JP-8 are occasionally exposed to benzene at levels above the current TLV. Among heavily exposed workers, uptake of JP-8 components occurs via both inhalation and dermal contact. Naphthalene in air and breath can serve as useful measures of exposure to JP-8 and uptake of fuel components in the body.
O ver the past 20 years kerosene based jet propellant type 8 (JP-8) has largely replaced gasoline based JP-4 as fuel for military aircraft and land vehicles in the USA and NATO. ${ }^{1}$ Because of its lower volatility, JP-8 is much less likely than JP-4 to explode following damage to fuel tanks. The commercial equivalent of JP-8 (Jet-A) is the primary jet fuel used worldwide, with about 240 billion litres consumed per year. ${ }^{2}$ Given its current rate of consumption (approximately 20 billion litres per year), JP-8 represents the single largest source of chemical exposure to military personnel in the USA and NATO. ${ }^{3}$ Personnel engaged in fuel maintenance and distribution can be heavily exposed to JP-8, both as a vapour and as the neat fuel. ${ }^{4}$

The toxicity of JP- 8 as well as its uptake and metabolism are poorly understood. ${ }^{5}$ Several gaps have been identified in current knowledge about exposure to JP-8 and potential health effects arising from these exposures. The problem is complicated by the heterogeneous and variable composition of the fuel, which contains thousands of hydrocarbons. Exposures to JP-8 have been quantified with measurements of total naphthas $\left(\mathrm{C}_{4}-\mathrm{C}_{16} \text { hydrocarbons }\right)^{6-8}$ as well as a proposed "fingerprint" of particular $\mathrm{C}_{9}-\mathrm{C}_{12}$ hydrocarbons. ${ }^{4}$

In the current study, we investigated exposures to two important aromatic constituents of JP-8, namely benzene and naphthalene. Although benzene is found at concentrations below $0.02 \%$ in $\mathrm{JP}^{-8} \mathrm{r}^{7-9}$ it is a known human carcinoge ${ }^{10}$ and is arguably the most hazardous component of jet fuel. Thus, we wished to quantify benzene exposures among a large sample of persons exposed to JP-8. Naphthalene is an abundant aromatic constituent of JP-8, reported at concentrations from $0.26 \%$ to $1 \%,{ }^{11}{ }^{12}$ and has been used as a marker of JP-8 in studies of dermal absorption. ${ }^{12-14}$ Although naphthalene has recently been shown to cause lung tumours in mice ${ }^{15}$ and may represent a health hazard in its own right, our interest here was to determine whether naphthalene might serve as a surrogate for JP-8 exposure and uptake in studies of health effects.

Since maintenance of aircraft fuel tanks involves respiratory protection and dermal contact with neat jet fuel, ${ }^{8}$ biomarkers have been recommended to assess total body exposure to JP$8 .{ }^{4}{ }^{16}$ Towards this end, we explored breath concentrations of benzene and naphthalene as biomarkers of exposure to JP-8, extending earlier investigations of benzene exposure and uptake during automobile refuelling and repair. ${ }^{17} 18$

\section{METHODS}

\section{Determination of benzene and naphthalene in JP-8} samples

Benzene and naphthalene concentrations were determined in 14 bulk samples of JP-8 obtained from seven Air Force bases, including six bases from the current investigation. Fuel samples were obtained from aircraft during removal of fuel prior to maintenance $(n=10)$ or from fuel trucks prior to aircraft fuelling $(n=4)$. Samples were sealed in $4 \mathrm{ml}$ glass vials capped with Teflon septa. Aliquots of JP-8 were diluted $1 / 1000$ with hexane containing $8.3 \mu \mathrm{g}$ of chlorobenzene as an internal standard. Aliquots of $2 \mu \mathrm{l}$ were injected in split mode (1/100) into a Hewlett Packard Model 5890 Series II GC equipped with a model 5971A mass selective detector. The DB- 1 column was $15 \mathrm{~m} \times 0.25 \mathrm{~mm}$ internal diameter with a $0.25 \mu \mathrm{m}$ film thickness (J\&W Scientific), with high purity helium used as carrier gas at $1.5 \mathrm{ml} / \mathrm{min}$. The column oven was held at $40^{\circ} \mathrm{C}$ for five minutes, increased at $5.5^{\circ} \mathrm{C} / \mathrm{min}$ to $90^{\circ} \mathrm{C}$ and then at $50^{\circ} \mathrm{C} /$ min to $260^{\circ} \mathrm{C}$, which was held for five minutes. Inlet and detector temperatures were $250^{\circ} \mathrm{C}$ and $280^{\circ} \mathrm{C}$, respectively. Masses at $\mathrm{m} / \mathrm{z} 78,112$, and 128 were monitored for benzene (retention time $=2.18 \mathrm{~min}$ ), chlorobenzene (retention time $=2.91 \mathrm{~min}$ ), and naphthalene (retention time $=12.85 \mathrm{~min}$ ), respectively, using electron impact ionisation with selective ion monitoring. 
Main messages

- Despite low benzene concentrations in jet fuel, benzene exposures were occasionally measured at levels above the 2002 TLV.

- Airborne naphthalene was highly correlated with known exposures to JP-8 and was not unduly influenced by other environmental sources.

- Benzene appears to be absorbed mainly by inhalation while naphthalene is absorbed by a combination of inhalation and dermal contact.

\section{Study subjects}

This investigation was part of a study of acute physiological effects and neurobehavioural impairment of US Air Force personnel exposed to JP-8. All protocols regarding recruitment and treatment of human subjects had been approved by the institutional review boards of the participating investigators. Personnel were recruited, with written informed consent, from six US Air Force bases housing C-130 transport or F-15 fighter aircraft. Each subject was assigned to one of three exposure categories (low, moderate, or high) based on the primary career field (US Air Force Specialty Code). Fuel maintenance workers were assigned to the high exposure category and their schedules were coordinated to ensure that procedures requiring tank entry were performed during surveys. Subjects with regular contact with jet fuel via fuel handling, distribution, recovery, and testing were assigned to the moderate exposure category. Subjects without contact to JP-8, such as military police, were assigned to the low exposure category.

\section{Exposure and breath monitoring}

Personal exposures to benzene and naphthalene were monitored for approximately four hours with monitors clipped to the subjects' collars. Air sampling employed passive monitors containing $0.1 \mathrm{~g}$ of $20 / 35$ mesh Tenax TA. ${ }^{17}{ }^{18}$ The sampling rate for benzene had been determined to be $1.30 \mathrm{ng} / \mathrm{min} / \mathrm{ppm}$ for these monitors. In the current study, we estimated an uptake rate of 1.36 (SE 0.03) ng/ppm/ min for naphthalene by exposing two sets of five monitors for four hours to a dynamic atmosphere of $419 \mu \mathrm{g} / \mathrm{m}^{3}$.

All subjects provided samples of end-exhaled air (hereafter "breath") at a central testing site at the beginning and end of the monitoring period. These are designated as "preexposure" and "post-exposure" breath samples, respectively. Most fuel maintenance workers provided an additional breath sample immediately after work and before travelling to the central testing site; these are designated as "end of exposure" breath samples. Breath samples were collected in $75 \mathrm{ml}$ glass bulbs as previously described. ${ }^{17}{ }^{18}$ On receipt at the laboratory, breath samplers were checked for loose or deformed caps and for the presence of condensed water vapour as indicators of sample integrity. ${ }^{18}$

\section{Analysis of monitors}

All monitors were shielded from light and stored at room temperature for up to three weeks. Prior to analysis, breath samples were passively transferred from the glass bulbs to sorbent tubes as previously described..$^{18}$ Sorbent tubes were thermally desorbed with a Perkin Elmer ATD 400 automatic thermal desorption system (Perkin Elmer, Norwalk, CT) for two minutes at $225^{\circ} \mathrm{C}$ to transfer analytes onto a Tenax packed, cryogen-free focusing cold trap maintained at $-30^{\circ} \mathrm{C}$. The cold trap was then rapidly heated to $225^{\circ} \mathrm{C}$ and held at that temperature for 0.3 minutes to transfer the contents to
Policy implications

- Naphthalene in environmental air and breath appear to be useful surrogates for exposure to jet fuel in studies of health effects.

- Since components of jet fuel appear to be absorbed through the skin, techniques to reduce dermal exposure are needed.

- Increasing cross ventilation and minimising the manipulation of fire suppression foam during maintenance of fuel systems can significantly reduce exposure to JP-8.

the analytical column via a fused silica transfer line, maintained at $200^{\circ} \mathrm{C}$. No inlet or outlet splitting was used.

Samples were analysed with a Hewlett Packard 6890 Series II gas chromatograph (Hewlett Packard Corp., Palo Alto, CA) equipped with a photoionisation detector (PID) containing a 9.5 eV lamp (model PI-52-02A, HNU Systems, Inc., Newton, MA) and a DB- l column of $60 \mathrm{~m} \times 0.53 \mathrm{~mm}$ internal diameter (1.5 $\mu \mathrm{m}$ film thickness) (J\&W Scientific, Folsom, CA). Ultrahigh purity helium was used as the carrier gas at a flow of $8 \mathrm{ml} / \mathrm{min}$. The oven temperature was held at $40^{\circ} \mathrm{C}$ for five minutes, increased at $10^{\circ} \mathrm{C} / \mathrm{min}$ to $75^{\circ} \mathrm{C}$, then increased at $5.5^{\circ} \mathrm{C} / \mathrm{min}$ to $175^{\circ} \mathrm{C}$, and finally increased at $50^{\circ} \mathrm{C} / \mathrm{min}$ to a final temperature of $260^{\circ} \mathrm{C}$ where it was held for six minutes. Chromatograms were manually integrated using Hewlett Packard ChemStation software. Benzene and naphthalene were identified by the retention times of 6.05 minutes and 21.95 minutes, respectively.

Samples were quantified against external benzene standards, consisting of sorbent tubes spiked with known amounts of benzene (in small volumes of air withdrawn from Tedlar bags) and naphthalene ( $2 \mu \mathrm{l}$ of hexane solution injected directly into the sorbent). The limits of quantitation (LOQs, based on three times the average peaks from unexposed air samplers) were 1.5 and $0.5 \mu \mathrm{g} / \mathrm{m}^{3}$ for benzene and naphthalene, respectively, in the breath monitors and $1.0 \mu \mathrm{g} / \mathrm{m}^{3}$ for both compounds in the air monitors (four hour sampling duration).

\section{Questionnaires}

Each participant completed a questionnaire requesting information about personal characteristics, work history, and tobacco use. Fuel maintenance personnel provided additional information about work tasks, protective equipment, ventilation, and environmental conditions. Covariates for multiple regression analyses were gleaned from these responses.

\section{Statistical analyses}

All statistical analyses were performed using SAS Statistical Software (v.8.02, SAS Institute, Cary, NC). Breath samples failing to satisfy requirements for quality control (loose caps and/or lack of condensed water vapour) were excluded from statistical analysis. Observations below the LOQ were assigned values of $2 / 3$ LOQ prior to statistical analysis. ${ }^{19}$ Benzene and naphthalene concentrations in breath were compared pre- and post-exposure using linear rank-sum tests for medians available with the NPARIWAY procedure of SAS. All other analyses employed logarithmic transformation to remove heteroscedasticity and to satisfy normality assumptions. Differences in air and breath levels among the three exposure categories were tested separately (four different models) using one way analysis of variance (ANOVA) procedures, with Bonferroni adjustment for multiple comparisons, available with the GLM procedure of SAS. 
Biological half times were estimated with the MIXED procedure of SAS by regressing the logged breath level of benzene or naphthalene on time post-exposure using "end of exposure" and "post-exposure" samples (time lag: 11$101 \mathrm{~min}$, median $=34 \mathrm{~min}$ ). Regression was restricted to measurements with values above the LOQ that decreased with time, using a mixed effects model with a random intercept and common slope among subjects.

Multiple linear regression analysis was performed, using the GLM procedure of SAS, to investigate effects of covariates on naphthalene concentrations in air or breath and on benzene concentrations in breath of fuel maintenance workers. The following model was employed:

$$
\begin{aligned}
& \text { for } i=1,2, \ldots, k \text { workers, and } \\
& Y_{i}=\ln \left(X_{i}\right)=\mu_{y}+\sum_{m=1}^{p} \delta_{m} C_{m i}+\varepsilon_{i}
\end{aligned}
$$

for $m=1,2, \ldots, p$ covariates,

where $X_{i}$ represents the benzene or naphthalene concentration in air or breath for the $i$-th worker, and $Y_{i}$ is the natural $\log$ transformed value of $X_{i} . Y_{i}$ represents the sum of the effects consisting of: $\mu_{y}$ representing the true underlying fixed mean (logged) level for all workers, the regression coefficients $\delta_{1}, \delta_{2}, \ldots, \delta_{p}$ representing the fixed effects of the $p$ covariates $C_{1 i}, C_{2 i}, \ldots, C_{p i}$, and $\epsilon_{i}$ representing the residual error for the $i$-th worker. Manual forward stepwise selection was used to build models. Dependent variables were first regressed on each independent variable separately to eliminate unlikely predictors, using a p value of 0.25 to screen covariates. Then, remaining variables were added sequentially, based on significance from the prior screening, and retained at a $\mathrm{p}$ value of 0.10 . Lastly, plausible interaction terms were tested. Standard regression diagnostics were performed. Extreme values were investigated for data input errors. Collinearity among the explanatory variables was investigated using Pearson correlation matrices and eigenvalues. Graphical analysis of residuals was performed to evaluate assumptions of linearity and homogeneity. Observations were evaluated for extreme values of leverage and influence (Cook's distance).

\section{RESULTS}

\section{Concentrations of benzene and naphthalene in JP- 8}

The estimated mean concentration $(\mathrm{w} / \mathrm{w})$ of benzene in 14 bulk samples of JP- 8 was $0.0051 \%$ ( SD $0.0038 \%$ ) with a range of $0.0002-0.0123 \%$. The mean concentration $(\mathrm{w} / \mathrm{w})$ of naphthalene in the same samples was $0.175 \%$ (SD 0.05\%) with a range of $0.109-0.266 \%$.

\section{Benzene and naphthalene in air and breath}

Table 1 summarises statistics of benzene in air and breath by exposure category. The median benzene concentrations in air were $3.1,7.4$, and $252 \mu \mathrm{g} / \mathrm{m}^{3}$ in the low, moderate, and high exposure categories, respectively, with an overall range of $<1.0-6630 \mu \mathrm{g} / \mathrm{m}^{3}$. The median "pre-exposure" breath concentrations were $4.7,5.8$, and $4.6 \mu \mathrm{g} / \mathrm{m}^{3}$ (range $<1.5-104 \mu \mathrm{g}$ / $\mathrm{m}^{3}$ ), and median "post-exposure" concentrations were 4.6, 9.0, and $11.4 \mu \mathrm{g} / \mathrm{m}^{3}$ (range $<1.5-153 \mu \mathrm{g} / \mathrm{m}^{3}$ ) in the three exposure categories. Table 2 summarises the corresponding levels of naphthalene in air and breath. The median naphthalene concentrations in air were 1.9, 10.3, and $485 \mu \mathrm{g} / \mathrm{m}^{3}$ in the three exposure categories, respectively, with an overall range of $<1.0-3910 \mu \mathrm{g} / \mathrm{m}^{3}$. The median "preexposure" concentrations of naphthalene in breath were below or near the LOQ in all three categories $(<0.5,0.58$, and $<0.5 \mu \mathrm{g} / \mathrm{m}^{3}$ ) with an overall range of $<0.5-36.3 \mu \mathrm{g} / \mathrm{m}^{3}$. The median "post-exposure" concentrations of naphthalene in breath were $0.73,0.93$, and $1.83 \mu \mathrm{g} / \mathrm{m}^{3}$ (range: $<0.5-15.8 \mu \mathrm{g}$ / $\mathrm{m}^{3}$ ) in the three exposure categories, with about one third of the concentrations in the low and moderate exposure categories below the LOQ.

As shown in table 3, both benzene and naphthalene exposures differed significantly among the three exposure categories $(p<0.0001)$. Levels in "post-exposure" breath were significantly different between the high and low $(\mathrm{p}<0.0001)$ and high and moderate $(\mathrm{p}<0.01$ for benzene, $\mathrm{p}<0.0001$ for naphthalene) categories, but the difference between the moderate and low categories was not significant for either compound $(\mathrm{p}>0.05)$.

The median breath concentrations in "end of exposure" samples (subjects in the high exposure category only) were $13.4 \mu \mathrm{g}$ benzene $/ \mathrm{m}^{3}$ (range $2.3-365 \mu \mathrm{g} / \mathrm{m}^{3}$ ) and $6.8 \mu \mathrm{g}$ naphthalene $/ \mathrm{m}^{3}$ (range $0.66-75.8 \mu \mathrm{g} / \mathrm{m}^{3}$ ).

\section{Relations between air and breath levels}

Figure 1 depicts scatter plots of (logged) benzene and naphthalene concentrations in breath and air for the three exposure categories. Among all subjects, significant linear correlations were observed for both benzene (Pearson $r=0.546, \mathrm{n}=290, \mathrm{p}<0.0001)$ and naphthalene $(r=0.671$, $\mathrm{n}=279, \mathrm{p}<0.0001)$. When stratified by exposure category, correlation coefficients increased from low, to moderate, to high exposure categories (benzene: $r=0.179(\mathrm{p}=0.04)$, $0.241(\mathrm{p}=0.16)$, and $0.585(\mathrm{p}<0.0001) ;$ naphthalene: $r=0.272 \quad(\mathrm{p}=0.002), \quad 0.438 \quad(\mathrm{p}=0.0085), \quad$ and 0.621 $(\mathrm{p}<0.0001))$. Among subjects in the high exposure category, larger correlation coefficients were observed in "end of exposure" samples than in "post-exposure" samples, with $r=0.702(\mathrm{n}=107, \mathrm{p}<0.0001)$ for benzene and $r=0.674$ $(\mathrm{n}=104, \mathrm{p}<0.0001)$ for naphthalene.

\section{Multiple linear regression}

Table 4 shows the final multiple regression model for naphthalene in air (AIR) $\left(r^{2}=0.643\right)$. The following covariates were significant predictors of $\ln (\mathrm{AIR})$ : primary job role (ROLE; entrant, attendant, other), purpose of work (PURPOSE; inspect, find leak, repair, other), foam storage location (STOREFOAM; wing, floor, enclosed container)* temperature (TEMPERATURE; $10-21{ }^{\circ} \mathrm{C}, 22-32^{\circ} \mathrm{C},>32^{\circ} \mathrm{C}$ ), cross ventilation (CROSSVENT; yes or no), and distance of the worker from the fuel tank (TANKDIST; inside, less than $3 \mathrm{~m}$, more than $3 \mathrm{~m}$ ).

Table 5 shows the final multiple regression model for benzene in post-exposure breath [ $\ln ($ POSTBREATH $)]$ $\left(r^{2}=0.619\right)$. The following significant predictors were observed: benzene air concentration $\ln (\mathrm{AIR})$, pre-exposure breath concentration $[\ln ($ PREBREATH $)]$, self reported tobacco smoking on day of sampling (SMOKED; yes or no), level of physical exertion on day of sampling (EXERTION, self reported ordinal scale from 0 to 24), self reported skin irritation (IRRITATION, yes or no), self reported respirator use (RESPIRATOR, yes or no), and time between end of exposure and post-exposure breath samples (TRAVELTIME, min).

Table 6 presents the significant predictors of "postexposure" naphthalene concentrations in breath [ln(POSTBREATH) $\left(r^{2}=0.656\right)$. This model included the following variables: naphthalene air concentration $\ln (\mathrm{AIR})$, self reported skin irritation (IRRITATION), tank fuel vapour purge method (PURGE, supplied air, exhaust, combination), method of fuel tank entry (HOWENTER, did not enter,

*Fuel tanks of some military aircraft are packed with polyurethane foam to reduce the risk of fire or explosion if the tank were to be ruptured during combat and to minimise fuel shifting during combat manoeuvres. The fuel soaked foam must be manually removed, stored in the workplace, and replaced during fuel tank maintenance. 
Table 1 Concentrations of benzene $\left(\mu \mathrm{g} / \mathrm{m}^{3}\right)$ in environmental air and in breath

\begin{tabular}{|c|c|c|c|c|c|c|c|c|c|}
\hline Variable & $\begin{array}{l}\text { Exposure } \\
\text { category }\end{array}$ & $\mathbf{n}$ & No. $<\mathrm{LOQ}$ & $\%<\mathbf{L O Q}$ & Min & $\begin{array}{l}\text { Lower } \\
\text { quartile }\end{array}$ & Median & $\begin{array}{l}\text { Upper } \\
\text { quartile }\end{array}$ & Max \\
\hline \multirow[t]{3}{*}{ Benzene in air } & High & 114 & 0 & 0 & 6.1 & 75.7 & 252 & 864 & 6630 \\
\hline & Moderate & 38 & 0 & 0 & 1.4 & 4.0 & 7.4 & 32.5 & 1850 \\
\hline & Low & 140 & 1 & 0.7 & $<1.0$ & 2.2 & 3.1 & 4.8 & 61.3 \\
\hline \multirow{3}{*}{$\begin{array}{l}\text { Benzene in breath, } \\
\text { pre-exposure }\end{array}$} & High & 111 & 19 & 17.1 & $<1.5$ & 2.6 & 4.6 & 8.2 & 30.4 \\
\hline & Moderate & 44 & 3 & 6.8 & $<1.5$ & 3.7 & 5.8 & 9.3 & 25.2 \\
\hline & Low & 151 & 23 & 15.2 & $<1.5$ & 2.9 & 4.7 & 7.4 & 104 \\
\hline $\begin{array}{l}\text { Benzene in breath, } \\
\text { end of exposure }\end{array}$ & High & 107 & 0 & 0 & 2.3 & 8.4 & 13.7 & 29.2 & 365 \\
\hline \multirow{3}{*}{$\begin{array}{l}\text { Benzene in breath, } \\
\text { post-exposure }\end{array}$} & High & 114 & 2 & 1.8 & $<1.5$ & 6.5 & 11.4 & 24.4 & 153 \\
\hline & Moderate & 41 & 3 & 7.3 & $<1.5$ & 3.6 & 9.0 & 20.3 & 58.1 \\
\hline & Low & 143 & 11 & 7.7 & $<1.5$ & 3.1 & 4.6 & 7.8 & 49.9 \\
\hline
\end{tabular}

from top, from bottom), and ambient temperature (TEMPERATURE).

\section{Elimination half times}

Using mixed models, the elimination rate constants $(k)$ for benzene and naphthalene in breath were estimated as the regression coefficients of $\ln$ (POSTBREATH) on time after exposure (h). The estimates of $k$ were $0.995 \mathrm{~h}^{-1}$ (half time $=$ $41.8 \mathrm{~min} ; 95 \%$ CI 36.5 to $48.8 \mathrm{~min}$ ) for benzene and $1.93 \mathrm{~h}^{-1}$ (half time $=21.6 \mathrm{~min} ; 95 \%$ CI 18.9 to $25.0 \mathrm{~min}$ ) for naphthalene.

\section{DISCUSSION}

\section{Benzene exposures among Air Force personnel}

Benzene exposure levels among workers in the moderate exposure category were generally low (median $7.4 \mu \mathrm{g} / \mathrm{m}^{3}$ ), consistent with results from recent studies of similar jet fuel exposed populations. Puhala and colleagues ${ }^{7}$ reported full shift exposures of $18.3 \mu \mathrm{g} / \mathrm{m}^{3}$ during the handling, distribution, or recovery of jet fuels and $20.7 \mu \mathrm{g} / \mathrm{m}^{3}$ during routine aircraft maintenance; Smith and colleagues ${ }^{6}$ reported full shift exposures of 24.1 and $8.0 \mu \mathrm{g} / \mathrm{m}^{3}$ for jet fuel distribution workers and engine mechanics, respectively.

The median benzene exposure during fuel maintenance activities (high exposure category) was $252 \mu \mathrm{g} / \mathrm{m}^{3}$, which was about 34 -fold higher than that for other fuel related work (moderate exposure category). The large range of exposures in the high exposure category $\left(6.1-6630 \mu \mathrm{g} / \mathrm{m}^{3}\right)$ is consistent with the results of Pleil and colleagues, ${ }^{4}$ who reported mean benzene concentrations of $17.6 \mathrm{ppb}(56.4 \mu \mathrm{g} /$ $\left.\mathrm{m}^{3}\right)$ around aircraft $(\mathrm{n}=9)$ and $2990 \mathrm{ppb}\left(9540 \mu \mathrm{g} / \mathrm{m}^{3}\right)$ inside fuel tanks $(n=16)$ during fuel system maintenance.

Chronic exposure to benzene at high concentrations is toxic to the haematopoietic system, potentially resulting in bone marrow damage, aplastic anaemia, and leukaemia. ${ }^{10} 20$
Two fuel distribution workers (5\% of subjects in the moderate exposure category) and 21 fuel maintenance workers (15\% of subjects in the high exposure category) were exposed to benzene above the $2002 \mathrm{TLV}$ of $1.6 \mathrm{mg} / \mathrm{m}^{3}$. These values indicate that exposure to benzene could pose a health hazard among personnel involved with the handling and maintenance of jet fuel. This hazard, however, is reduced by the required use of respiratory protection while inside the fuel tanks.

While benzene exposures clearly increased among workers assigned a priori to low, moderate, and high exposure categories (table 1), there was substantial overlap of air levels in all categories (fig 1). Since the categories had been assigned on the basis of known patterns of JP-8 exposure, this suggests that sources other than JP-8 contributed significantly to benzene exposure among these personnel. This is not surprising given the myriad of known environmental sources of benzene, including gasoline, engine exhausts, and cigarette smoke. ${ }^{21} 22$ Evidence that these workers had been exposed to benzene from sources other than JP-8 is found in the model of benzene in "postexposure" breath (table 5), where the "pre-exposure" breath concentration and recent smoking were both significant covariates. So despite the fact that fuel handling and maintenance can lead to excessive benzene exposures (as shown above), it would be inappropriate to use benzene as a surrogate for JP-8 exposure.

\section{Naphthalene as a surrogate for JP-8}

Unlike the situation for benzene, exposure to naphthalene showed virtually no overlap among workers assigned a priori to the low and high exposure categories (fig 1). This is consistent with the nature of exposure to JP- 8 because highly exposed workers were selected based on unambiguous nearfield exposure to jet fuel while those placed in the low

Table 2 Concentrations of naphthalene $\left(\mu \mathrm{g} / \mathrm{m}^{3}\right)$ in environmental air and in breath

\begin{tabular}{|c|c|c|c|c|c|c|c|c|c|}
\hline Variable & $\begin{array}{l}\text { Exposure } \\
\text { category }\end{array}$ & $\mathbf{n}$ & No. $<$ LOQ & $\%<\mathbf{L O Q}$ & Min & Lower quartile & Median & Upper quartile & Max \\
\hline \multirow[t]{3}{*}{ Naphthalene in air } & High & 113 & 0 & 0 & 12.8 & 179 & 485 & 867 & 3910 \\
\hline & Moderate & 38 & 3 & 7.9 & $<1.0$ & 2.2 & 10.3 & 29.8 & 932 \\
\hline & Low & 139 & 30 & 21.6 & $<1.0$ & 1.1 & 1.9 & 3.2 & 16.9 \\
\hline Naphthalene in & High & 112 & 77 & 68.8 & $<0.5$ & $<0.5$ & $<0.5$ & 0.6 & 6.1 \\
\hline breath, pre- & Moderate & 43 & 20 & 46.5 & $<0.5$ & $<0.5$ & 0.6 & 0.8 & 16.1 \\
\hline exposure & Low & 149 & 89 & 59.7 & $<0.5$ & $<0.5$ & $<0.5$ & 0.7 & 36.3 \\
\hline $\begin{array}{l}\text { Naphthalene in } \\
\text { breath, end of } \\
\text { exposure }\end{array}$ & High & 104 & 0 & 0 & 0.7 & 2.6 & 6.0 & 16.1 & 75.8 \\
\hline Naphthalene in & High & 111 & 7 & 6.3 & $<0.5$ & 0.9 & 1.83 & 4.0 & 15.8 \\
\hline breath, post- & Moderate & 40 & 12 & 30.0 & $<0.5$ & $<0.5$ & 0.93 & 1.9 & 13.0 \\
\hline exposure & Low & 143 & 51 & 35.7 & $<0.5$ & $<0.5$ & 0.73 & 1.0 & 6.9 \\
\hline
\end{tabular}

$L O Q$, limit of quantitation. 
Table 3 Levels of significance ( $p$ value)* for tests of differences between means of logged concentrations of benzene and naphthalene in air and in post-exposure breath

\begin{tabular}{llllll}
\hline \multirow{2}{*}{ Comparison } & \multicolumn{2}{l}{ Concentration in air } & & \multicolumn{2}{l}{ Concentration in breath } \\
\cline { 2 - 3 } \cline { 5 - 6 } & Benzene & Naphthalene & & Benzene & Naphthalene \\
\hline Low $v$ moderate & $<0.0001$ & $<0.0001$ & & NS & NS \\
Moderate $v$ high & $<0.0001$ & $<0.0001$ & & $<0.01$ & $<0.0001$ \\
Low $v$ high & $<0.0001$ & $<0.0001$ & & $<0.0001$ & $<0.0001$ \\
\hline
\end{tabular}

*With Bonferroni correction for multiple comparisons. $N S$, not significant $(p>0.05)$.

category had only background, far-field exposures. Thus, even though naphthalene is a natural combustion product of organic materials ${ }^{15}$ and is also present at low levels in gasoline and cigarette smoke, ${ }^{23-25}$ these background sources of naphthalene were trivial compared to JP-8 in our study.

It is also worth mentioning that naphthalene concentrations measured in the low exposure category (table 2, median $1.9 \mu \mathrm{g} / \mathrm{m}^{3}$, interquartile range $1.1-3.2 \mu \mathrm{g} / \mathrm{m}^{3}$ ) were greater than those reported in ambient air at levels of $0.3-0.7 \mu \mathrm{g} / \mathrm{m}^{3}$ at locations other than Air Force bases. ${ }^{26}$ This supports previous speculation ${ }^{47}$ that essentially all Air Force personnel have incidental exposure to jet fuel vapours and exhaust emanating from aircraft and ground support equipment.

The multiple linear regression model for naphthalene exposure (table 4) included the following covariates: the worker's primary role, the purpose of maintenance, the location for foam storage, the ambient temperature, the presence of cross ventilation, and the distance of the worker from the fuel tank. The directions of these effects are generally logical if naphthalene were indeed a good predictor of JP-8 exposure. For example, the role designated as "entrant" was associated with higher exposure levels, as expected since concentrations of jet fuel are increased inside the fuel tanks. ${ }^{48}$ Likewise, those primarily working inside the fuel tank had the highest exposures while air levels diminished with distance from the tank. Lower exposures were observed at higher temperatures (less time can be spent inside the tank on hot days due to heat stress), when explosion suppression foam was stored on the wing (which requires less handling than transporting it to the floor), and when cross ventilation was present.

\section{Breath concentrations of benzene and naphthalene}

While concentrations of naphthalene were higher than concentrations of benzene in air, median naphthalene levels were lower than those of benzene in "post-exposure" breath. This points to the lower vapour pressure of naphthalene compared to benzene $\left(0.082 v 95.3 \mathrm{~mm} \mathrm{Hg} \text { at } 25^{\circ} \mathrm{C}\right)^{26}$ and the much higher estimated blood-air partition coefficient (based on log octanol-water partition coefficients of 3.39 for naphthalene and 2.13 for benzene). ${ }^{15}$

Concentrations of both benzene and naphthalene were significantly higher in "post-exposure" breath than in "preexposure" breath in the moderate and high exposure
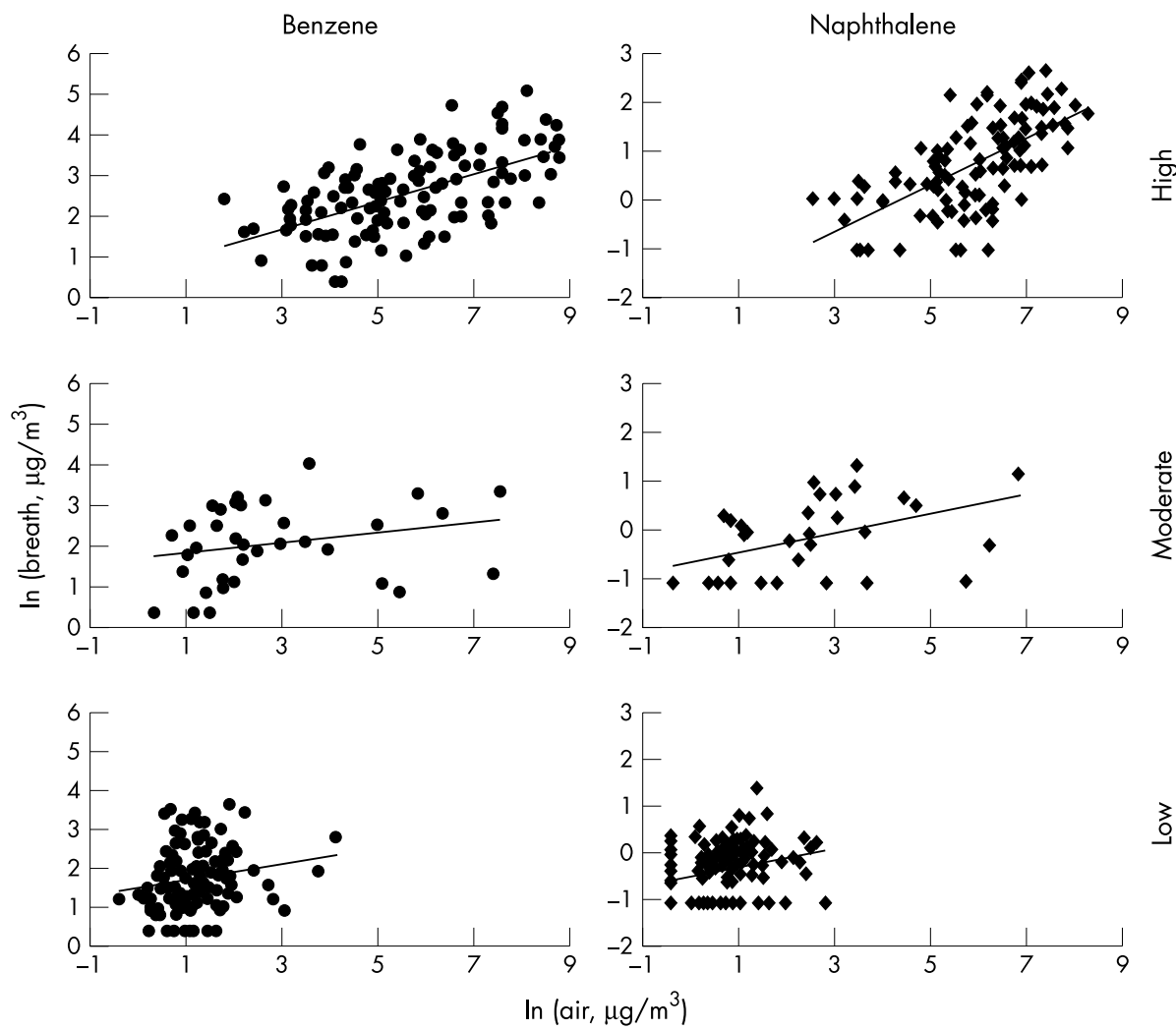

Figure 1 Relations between concentrations in air and breath, by exposure category, for benzene (high: $r=0.585, \mathrm{n}=114 ;$ moderate: $r=0.241$, $\mathrm{n}=35$; low: $r=0.179, \mathrm{n}=130$ ) and naphthalene (high: $r=0.621, \mathrm{n}=109$; moderate: $r=0.438, \mathrm{n}=35$; low: $r=0.272, \mathrm{n}=126$ ). 


\begin{tabular}{|c|c|c|c|c|}
\hline Effect & $\mathrm{n}$ & Estimate & SE & $P$ value \\
\hline Intercept & 111 & 6.400 & 0.551 & $<0.0001$ \\
\hline ROLE & & - & - & 0.0006 \\
\hline Entrant & 79 & 0 & - & - \\
\hline Attendant & 25 & -0.881 & 0.228 & 0.0002 \\
\hline Other & 7 & -0.808 & 0.348 & 0.0223 \\
\hline PURPOSE & & - & - & 0.0027 \\
\hline Inspect & 55 & 0 & - & - \\
\hline Find leak & 7 & -1.233 & 0.330 & 0.0180 \\
\hline Repair & 30 & -0.239 & 0.189 & 0.4073 \\
\hline Other & 19 & -0.434 & 0.235 & 0.0678 \\
\hline STOREFOAM & & - & - & $<0.0001$ \\
\hline Wing & 43 & -1.669 & 0.344 & $<0.0001$ \\
\hline Floor & 2 & -0.290 & 0.336 & 0.3898 \\
\hline Enclosed & 6 & 0 & - & - \\
\hline TEMPERATURE & & - & - & 0.0354 \\
\hline $10-21{ }^{\circ} \mathrm{C}$ & 7 & 0.885 & 0.339 & 0.0104 \\
\hline $21-32^{\circ} \mathrm{C}$ & 77 & 0.168 & 0.184 & 0.3657 \\
\hline$>32^{\circ} \mathrm{C}$ & 27 & 0 & - & - \\
\hline CROSSVENT & & - & - & 0.0293 \\
\hline Yes & 57 & -0.347 & 0.157 & 0.0293 \\
\hline No & 54 & 0 & - & - \\
\hline TANKDIST & & - & - & 0.0357 \\
\hline Inside & 64 & 0.981 & 0.408 & 0.0180 \\
\hline$<3 \mathrm{~m}$ & 42 & 0.621 & 0.385 & 0.1102 \\
\hline$>3 m$ & 5 & 0 & - & - \\
\hline
\end{tabular}

categories (tables 1 and 2). This provides further evidence that JP-8 was a significant source of exposure to both compounds among Air Force personnel whose jobs required at least incidental contact with jet fuel. In the moderate exposure category, the difference between "pre-exposure" and "post-exposure" breath levels was more significant for naphthalene $(p=0.0063$, one sided Mann-Whitney $U)$ than for benzene $(p=0.0105)$, but in the high exposure category the difference was highly significant for both compounds $(\mathrm{p}<0.0001)$.

Comparisons of "post-exposure" breath concentrations across exposure categories (table 3) showed significant differences not only between the high and low exposure categories but also between the high and moderate exposure categories for both naphthalene and benzene. The level of significance for the difference between benzene concentrations in the moderate and high exposure categories was weaker than that for naphthalene $(\mathrm{p}<0.01 v \mathrm{p}<0.0001)$, presumably because benzene is more abundant in cigarette smoke. The difference in "post-exposure" breath levels between the low and moderate exposure categories was not significant for either compound $(\mathrm{p}>0.05)$ despite a highly significant difference in external exposures $(\mathrm{p}<0.0001)$.

\section{Predictors of benzene and naphthalene in breath}

The exposure-breath relations were weak for both benzene and naphthalene in the low and moderate exposure categories (fig 1). Although the corresponding relations were much stronger in the high exposure category, tremendous variability in breath levels was observed at a given exposure. Such great variability has been reported in other field investigations of benzene in breath. ${ }^{17} 2829$ Although breath levels of volatile organic compounds decay rapidly following exposure, $^{3031}$ air measurements were integrated over four

Table 5 Significant predictors of benzene concentrations in post-exposure breath of fuel maintenance workers

\begin{tabular}{llcll}
\hline Effect & \multicolumn{1}{l}{$\mathbf{n}$} & Estimate & \multicolumn{1}{l}{ SE } & p value \\
\hline Intercept & 108 & 1.319 & 0.323 & $<0.0001$ \\
AIR $\ln \left(\mu \mathrm{g} / \mathrm{m}^{3}\right)$ & 108 & 0.299 & 0.041 & $<0.0001$ \\
PREBREATH $\ln \left(\mu \mathrm{g} / \mathrm{m}^{3}\right)$ & 108 & 0.289 & 0.082 & 0.0006 \\
TRAVELTIME $(\mathrm{min})$ & 108 & -0.014 & 0.004 & 0.0009 \\
EXERTION & 108 & 0.031 & 0.014 & 0.0322 \\
SMOKED & & - & - & 0.0144 \\
Yes & 23 & 0.385 & 0.155 & 0.0144 \\
No & 85 & 0 & - & - \\
RESPIRATOR & & - & - & 0.0037 \\
Yes & 96 & -0.605 & 0.204 & 0.0037 \\
No & 12 & 0 & - & - \\
IRRITATION & & - & - & 0.0245 \\
Yes & 57 & 0.324 & 0.142 & 0.0245 \\
No & 51 & 0 & - & - \\
\hline
\end{tabular}

AIR, concentration of benzene in air; PREBREATH, concentration of benzene in pre-exposure breath; TRAVELTIME, time lag between end of exposure and breath sampling; EXERTION, ordinal level of physical activity (0-24); SMOKED, smoked cigarette(s) on the day of sampling; RESPIRATOR, used a respirator; IRRITATION, reported skin irritation. 
Table 6 Significant predictors of naphthalene concentrations in post-exposure breath of fuel maintenance workers

\begin{tabular}{|c|c|c|c|c|}
\hline Effect & $\mathrm{n}$ & Estimate & SE & $p$ value \\
\hline Intercept & 107 & -0.826 & 0.431 & 0.0584 \\
\hline AIR $\ln \left(\mu \mathrm{g} / \mathrm{m}^{3}\right)$ & 107 & 0.290 & 0.063 & $<0.0001$ \\
\hline IRRITATION & & - & - & 0.0466 \\
\hline Yes & 57 & 0.262 & 0.130 & 0.0466 \\
\hline No & 50 & 0 & - & - \\
\hline PURGE & & - & - & 0.0020 \\
\hline Blow & 93 & 0 & - & - \\
\hline Exhaust & 10 & 0.700 & 0.194 & 0.0005 \\
\hline Combination & 4 & 0.133 & 0.289 & 0.6469 \\
\hline HOWENTER & & - & - & $<.0001$ \\
\hline Did not & 17 & -0.385 & 0.223 & 0.0870 \\
\hline From top & 37 & -0.713 & 0.160 & $<0.0001$ \\
\hline From bottom & 53 & 0 & - & - \\
\hline TEMPERATURE & & - & - & 0.0235 \\
\hline $10-21{ }^{\circ} \mathrm{C}$ & 7 & -0.707 & 0.253 & 0.0063 \\
\hline $21-32^{\circ} \mathrm{C}$ & 75 & -0.164 & 0.134 & 0.2230 \\
\hline$>32^{\circ} \mathrm{C}$ & 25 & 0 & - & - \\
\hline
\end{tabular}

AIR, concentration of naphthalene in air; IRRITATION, reported skin irritation; PURGE, method of purging vapour from fuel tank; HOWENTER, method of entering fuel tank; TEMPERATURE, ambient temperature.

hours in our study; thus, the presence of high transient levels early in the work shift could explain some of the variability in exposure adjusted breath levels. Some variability can also be attributed to the uneven time lag ( 11 to $101 \mathrm{~min}$ ) between the end of exposure and the collection of "post-exposure" breath samples (air measurements were more highly correlated with "end of exposure" breath measurements than with "post-exposure" breath measurements).

Multivariable analyses yielded considerably different models of benzene and naphthalene in post-exposure breath (tables 5 and 6). As expected, significant predictors of benzene in breath included the concentrations of benzene in air and in "pre-exposure" breath. Other significant covariates included cigarette smoking, the time lag prior to breath sampling, respirator use, skin irritation, and the level of physical activity. All of these effects are logical. Cigarette smoking was associated with higher benzene concentrations due to the presence of benzene in cigarette smoke. ${ }^{22}$ Likewise, physical activity, which increases both breathing rate and cardiac output, ${ }^{32}$ increased levels of benzene in breath. Also, skin irritation was associated with higher levels of benzene in breath, suggesting that persons with substantial dermal exposure absorbed benzene through the skin. Moreover, the report of skin irritation was a much stronger predictor of benzene in breath than self reported dermal contact with jet fuel $(p=0.22$ using dermal contact rather than irritation in the final model). Lower breath concentrations of benzene were associated with longer time lags prior to breath sampling and with respirator use; these effects were also anticipated.

Although naphthalene is also found in tobacco smoke, albeit at much lower levels than benzene (1-3 $\mu \mathrm{g}$ naphthalene $v$ up to $57 \mu \mathrm{g}$ benzene per cigarette), ${ }^{22-25}$ cigarette smoking was not a significant predictor of naphthalene in post-exposure breath (table 5 ). This indicates that cigarette smoking should not confound analyses of JP-8 exposure among heavily exposed subjects. Interestingly, tank entry from the bottom of the aircraft was associated with higher breath levels, perhaps because opening a tank from the underside of the aircraft resulted in greater physical contact with fuel. This variable along with self reported skin irritation and ambient temperature suggest that dermal exposure may have played a particularly important role in naphthalene uptake. Indeed, naphthalene readily penetrates the intact skin, ${ }^{11}$ and JP-8 disrupts the barrier function of skin. ${ }^{13}$ Furthermore, after controlling for exposure in the model, naphthalene in breath increased with ambient temperature, suggesting that increased dermal blood flow facilitated greater dermal absorption..$^{33}$

Comparing the models for benzene and naphthalene in breath, the large difference between the intercepts is readily apparent. The larger intercept for benzene implies much higher background levels of benzene than naphthalene in the breath, an implication confirmed by the measurements of pre-exposure breath levels. The dissimilar predictors imply a keen difference in the role of dermal absorption. Respirator use, which was a particularly important determinant for benzene, was not a significant determinant for naphthalene. Physical exertion, which increases respiratory absorption, was also important only for benzene. On the other hand, factors that should increase dermal absorption (physical contact with fuel, ambient temperature) were more important for naphthalene. These results suggest that benzene was chiefly absorbed by inhalation among fuel maintenance workers while naphthalene was absorbed by a combination of inhalation and dermal contact. If inhalation exposure ceased on leaving the work area but dermal absorption continued, then the difference in absorption pathways can explain why the time lag between exposure and breath sampling was an important determinant of the "postexposure" breath concentration of benzene but not of naphthalene.

\section{Elimination half times of naphthalene and benzene}

Naphthalene is rapidly eliminated from the body due to efficient metabolism. The primary urinary metabolite of naphthalene, 1-naphthol, has a reported half life of approximately 4 hours, ${ }^{23}$ but we are unaware of any previously published values for the elimination half time of the parent compound. Using samples collected immediately after exposure at the work site ("end of exposure") and subsequent samples collected at the testing stations ("postexposure", median lag $34 \mathrm{~min}$ ) we estimated the elimination rate constant $(k)$ for naphthalene in breath to be $1.93 \mathrm{~h}^{-1}$, corresponding to a half time of $21.6 \mathrm{~min}$ (95\% CI 18.9 to $25.0 \mathrm{~min})$. This is much shorter than the elimination half time of benzene in the same samples, $41.8 \mathrm{~min}$ (95\% CI 18.9 to $25.0 \mathrm{~min}$ ), a value similar to those previously published for benzene elimination. ${ }^{31} 34$

\section{CONCLUSIONS}

We conclude that despite the low concentration of benzene in fuel, benzene exposure was significant among subjects 
having regular contact with JP-8. Indeed, $5 \%$ and $15 \%$ of benzene air measurements were above the 2002 TLV among workers in the moderate and high exposure categories, respectively.

Airborne naphthalene was highly correlated with a priori categories of JP-8 exposure and, unlike benzene, was not unduly influenced by background sources and cigarette smoking. Furthermore, among highly exposed personnel, several factors known to increase exposure to and uptake of JP-8 also increased exposure to and uptake of naphthalene. This suggests that naphthalene may be a good surrogate for JP-8 in studies of health effects associated with jet fuel. By modelling breath levels of naphthalene and benzene we infer that, whereas benzene was predominantly absorbed by inhalation, naphthalene was absorbed by a combination of inhalation and dermal contact. Thus, biomonitoring of naphthalene or its products in breath or urine should reflect both respiratory and dermal uptake of JP-8 and might be preferred to air monitoring for exposure assessment.

We also make specific recommendations to reduce exposures to JP-8 among fuel maintenance workers. First, since components of jet fuel appear to be absorbed through the skin, we recommend that techniques be investigated to reduce dermal exposure among these workers. Second, we encourage increased use of cross ventilation and reduced manipulation of fire suppression foam to reduce the uptake of JP-8 components during fuel maintenance.

\section{ACKNOWLEDGEMENTS}

This work was supported by the National Institute for Environmental Health Sciences through grants P42ES05948, P30ES10126, and T32ES07018 and by a contract with the US Air Force. We thank Maj. Les Smith (ret.) and SSgt. Doug Fritts for their assistance with collection of field data, and Rogelio Tornero-Velez and Suramya Waidyanatha for assistance with analytical methods.

\section{Authors' affiliations \\ P P Egeghy, L Hauf-Cabalo, S M Rappaport, Department of} Environmental Sciences and Engineering, School of Public Health, University of North Carolina at Chapel Hill, Chapel Hill, North Carolina 27599-7431, USA

R Gibson, Office of the Assistant Secretary of Defense (Health Affairs), Clinical and Program Policy, Skyline 5, Suite 601, 5111 Leesburg Pike, Falls Church, VA 22041-3206, USA

\section{REFERENCES}

1 Ritchie GD, Still KR, Alexander WK, et al. A review of the neurotoxicity risk of selected hydrocarbon fuels. J Toxicol Environ Health B 2001;4:223-312.

2 Armbrust Aviation Group. World jet fuel almanac. Palm Beach Gardens, FL: Armbrust Aviation Group, 1998

3 Henz K. Survey of jet fuels procured by the Defense Energy Support Center 1990-1996. Ft Belvoir, VA: Defense Logistics Agency, 1998.

4 Pleil JD, Smith LB, Zelnick SD. Personal expsosure to JP-8 jet fuel vapors and exhaust at Air Force Bases. Environ Health Perspect 2000;108:183-192.

5 ATSDR (Agency for Toxic Substances and Disease Registry). Toxicological profile for jet fuels (JP-5 and JP-8). Atlanta: ASTDR, 1998.

6 Smith LB, Bhattaacharya A, Lemasters G, et al. Effect of chronic low-level exposure to jet fuel on postural balance of US Air Force personnel. J Occup Environ Med 1997;39:623-32

7 Puhala E, Lemaster G, Smith L, et al. Jet fuel exposure in the United States Air Force. Appl Occup Environ Hyg 1997; 12:606-10.
8 Carlton GN, Smith LB. Exposures to jet fuel and benzene during aircraft fuel tank repair in the U.S. Air Force. Appl Occup Environ Hyg 2000;15:485-91. 9 IARC. Occupational exposures in petroleum refining; crude oil and major petroleum fuels. IARC Monogr Eval Carconog Risk Hum 1989;45:219-37.

10 IARC. Some industrial chemicals and dyestuffs. IARC Monogr Eval Carcinog Risk Hum 1982;29:95-148

11 McDougal JN, Pollard DL, Weisman W, et al. Assessment of skin absorption and penetration of JP-8 jet fuel and its components. Toxicol Sci 2000;55:247-55

12 Riviere JE, Brooks JD, Monteiro-Riviere NA, et al. Dermal absorption and distribution of topically dosed jet fuels Jet-A, JP-8, and JP-8(100). Toxicol Appl Pharmacol 1999; 160:60-75.

13 Kanikkannan N, Burton S, Patel R, et al. Percutaneous permeation and skin irritation of JP-8+100 jet fuel in a porcine model. Tox Letters $2001 ; 119: 133-42$

14 Kanikkannan N, Patel R, Jackson T, et al. Percutaneous absorption and skin irritation of JP-8 (jet fuel). Tox Letters $2001 ; 161: 1-11$.

15 NTP (National Toxicology Program). NTP Technical Report on the toxicology and carcinogenesis studies of naphthalene (CAS No. 91-20-3) in F344/N rats (inhalation studies). NTP TR 500, NIH Publication No. 01-4434, US Department of Health and Human Services, 2000.

16 Lemasters GK, Olsen DM, Yiin JH, et al. Male reproductive effects of solvent and fuel exposure during aircraft maintenance. Reprod Toxicol 1999:13:155-66.

17 Egeghy PP, Tornero-Velez R, Rappaport SM. Environmental and biological monitoring of benzene during self-service automobile refueling. Environ Health Perspect 2000;108:1 195-202.

18 Egeghy PP, Nylander-French L, Gwin KK, et al. Self-collected breath sampling for monitoring low-level benzene exposures among automobile mechanics. Ann Occup Hyg 2002;46:489-500.

19 Hornung RW, Reed LD. Estimation of average concentration in the presence of nondetectable values. Appl Occup Environ Hyg 1990;5:46-51.

20 Savitz DA, Andrews KW. Review of epidemiologic evidence on benzene and lymphatic and hematopoietic cancers. Am J Ind Med 1997;31:287-95.

21 Wallace L. Major sources of exposure to benzene and other volatile organic chemicals. Risk Anal 1990;10:59-64.

22 Wallace L. Environmental exposure to benzene: an update. Environ Health Perspect 1996; 104(suppl 6): 1129-36.

23 ATSDR (Agency for Toxic Substances and Disease Registry). Toxicological profile for naphthalene (update). Atlanta: ASTDR, 1995.

24 Schmeltz I, Tosk J, Hoffman D. Formation and determination of naphthalene in cigarette smoke. Anal Chem 1976;48:645-50.

25 Yang $M$, Koga $M$, Katoh $T$, et al. A study for the proper application of urinary naphthols, new biomarkers for airborne polycyclic aromatic hydrocarbons. Arch Environ Contam Toxicol 1999;36:99-108.

26 CARB (California Air Resources Board). Toxic Air Contaminant Identification List Summaries. http://www.arb.ca.gov/toxics/tac/factshts/naphthal.pdf. Sacramento, CA: Air Resources Board, 1997.

27 Childers JW, Witherspoon CL, Smith LB, et al. Real-time and integrated measurement of potential human exposure to particle-bound polycyclic aromatic hydrocarbons (PAHs) from aircraft exhaust. Environ Health Perspect 2000;108:853-62

28 Drummond L, Luck R, Afacan AS, et al. Biological monitoring of workers exposed to benzene in the coke oven industry. $\mathrm{Br} J$ Ind Med 1988:45:256-61.

29 Perbellini L, Faccini GB, Pasini $F$, et al. Environmental and occupational exposure to benzene by analysis of breath and blood. Br J Ind Med 1988;45:345-52.

30 Pleil JD, Lindstrom AB. Sample timing and mathematical considerations for modeling breath elimination of volatile organic compounds. Risk Anal 1998; 18:585-602.

31 Raymer JH, Pellizzari ED, Thomas KW, et al. Elimination of volatile organic compounds in breath after exposure to occupational and environmental microenvironments. J Expo Anal Environ Epidemiol 1991;1:439-51.

32 Droz PO, Fernandez JG. Effect of physical workload on retention and metabolism of inhaled organic solvents: a comparative theoretical approach and its application with regards to exposure monitoring. Int Arch Occup Environ Health 1977:38:231-46.

33 Corley RA, Gordon SM, Wallace LA. Physiologically based pharmacokinetic modeling of the temperature-dependent dermal absorption of chloroform by humans following bath water exposures. Toxicol Sci 2000;53:13-23.

34 Pekari K, Vainiotalo S, Heikkilä P, et al. Biological monitoring of occupational exposure to low levels of benzene. Scand J Work Environ Health 1992;18:317-22. 